\title{
ANEXO. \\ APLICACIÓN DIDÁCTICA DE LAS INTELIGENCIAS MÚLTIPLES
}

\section{$M^{a}$ del Pino Delgado Henríquez}

Colegio Santa Teresa de Jesús (Sevilla)

\section{PLANTILLAS DE OBSERVACIÓN PARA UNA EVALUACIÓN ALTERNATIVA.}

ANEXO I (NORMAS PRESENTACIÓN DE TRABAJOS ESCRITOS): 
Deberán usarse folios en blanco tamaño A-4. Se puede utilizar una plantilla con líneas rectas debajo del folio para evitar la caída de líneas...

Márgenes: superior e izquierdo (3 cm.), derecho e inferior $(2 \mathrm{~cm}$.)

El trabajo deberá ir escrito a mano, salvo la portada, índice y bibliografía, que podrán elaborarse con el ordenador, si se desea.

Renglones horizontales, la separación entre párrafos deberá ser mayor que entre líneas, y se debe sangrar la primera línea de cada párrafo.

No se debe abusar del subrayado, y en caso de usarlo deberá hacerse en el mismo color que el texto.

Se usará color azul o negro y nunca lápiz.

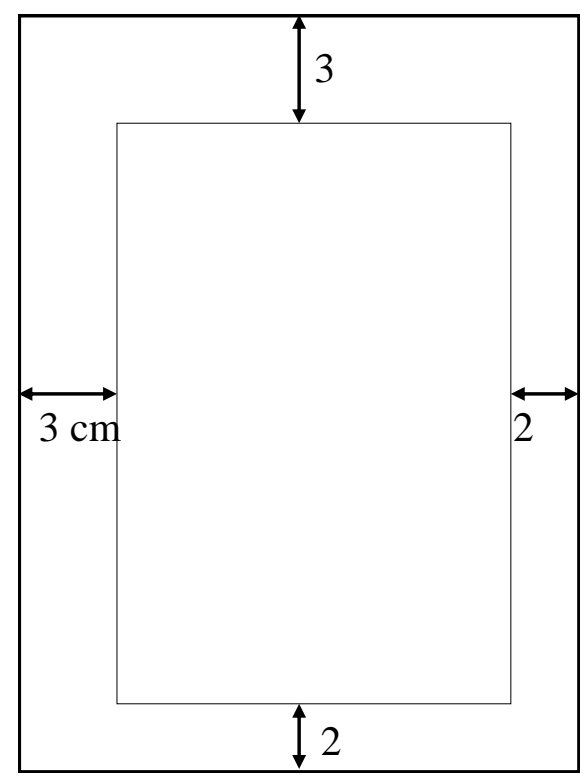

Las páginas del trabajo deberán ir numeradas, salvo la portada y el índice. La numeración deberá colocarse en la parte inferior de cada página y centrada, aproximadamente a un centímetro del borde inferior. 


\section{ELEMENTOS QUE DEBEN APARECER SIEMPRE EN UN TRABAJO.}

Portada, página en blanco, índice, el trabajo, bibliografía y contraportada.

La portada deberá llevar el nombre del centro al que pertenecemos, un título en letras grandes y centradas, y nuestros datos personales más la fecha de entrega del trabajo.

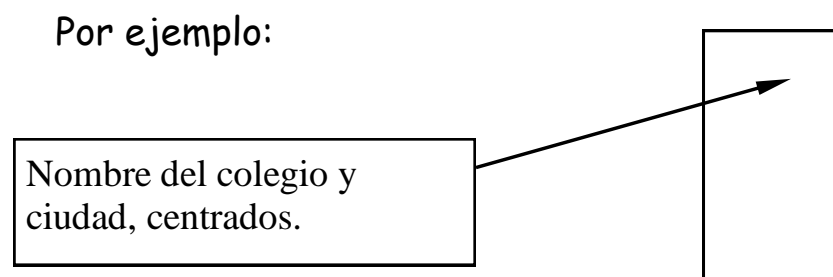

COLEGIO SANTA TERESA DE JESÚS

San Juan de Aznalfarache (Sevilla)

Título del trabajo, procurando no cortar nunca una palabra. $\mathrm{Si}$ el título es largo lo pondremos en varias líneas, pero siempre sin cortar palabras.

No conviene abusar de los colores en caso de usarlos.

Podemos añadir un pequeño dibujo o gráfico que haga referencia al contenido del trabajo. Puede ser una fotografía o ilustración pegada.

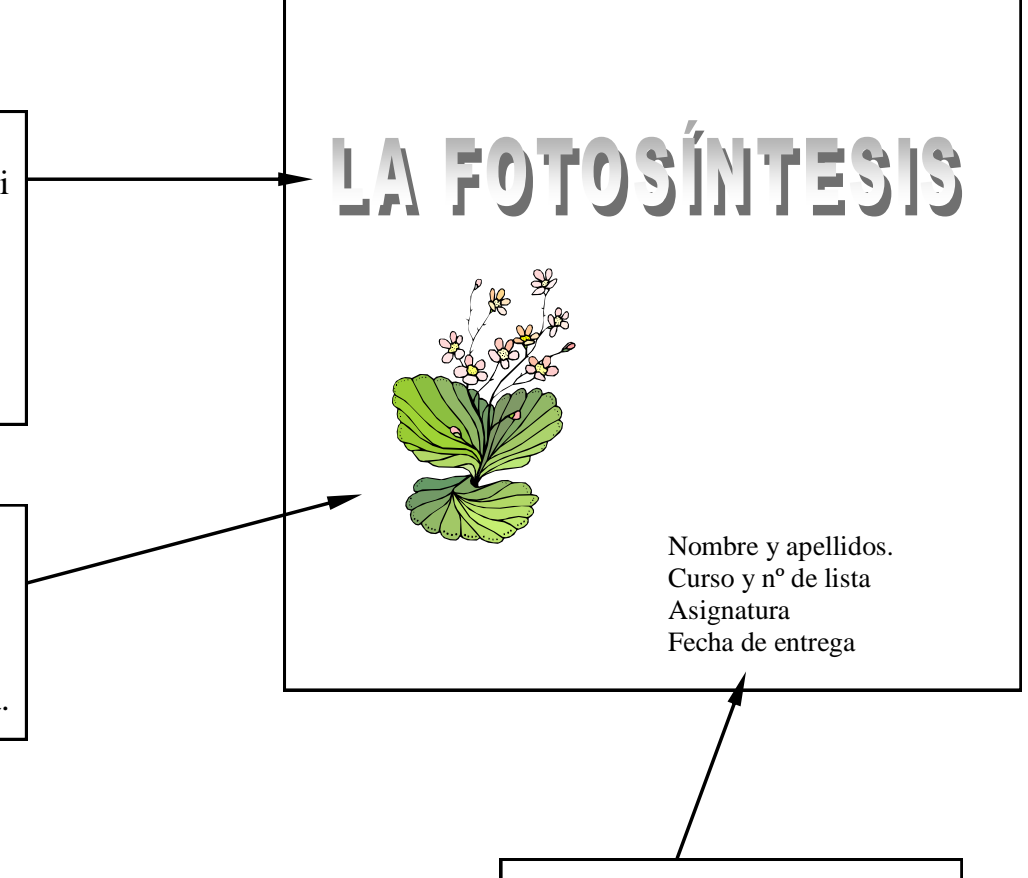

Datos personales: nombre y apellidos, curso, número de lista, asignatura y fecha de entrega del trabajo.

Página en blanco: Se coloca tras la portada y antes del índice. Esta hoja la puede usar el profesor que corrige el trabajo para poner la nota, hacer comentarios, etc.... 
El índice hay que elaborarlo una vez que esté terminado el trabajo, pues no es hasta entonces cuando sabremos las páginas que hemos utilizado y su numeración. Se coloca siempre tras la hoja en blanco y antes del propio trabajo.

Cuando elaboremos un trabajo, debemos ir poniendo títulos a cada parte que vayamos tratando. Esos títulos serán los que deberán aparecer en el índice con el número de la página en que comienzan. Cada título también puede ir numerado con números arábigos o romanos.

El trabajo en sí comienza a partir de ahora. Puede colocarse una introducción antes, hablando brevemente del contenido del trabajo, impresiones sobre el mismo, etc.

Bibliografía; en la bibliografía enumeraremos las fuentes que hemos consultado: libros, páginas Web, enciclopedias, publicaciones, etc. En el caso de libros además de su título, indicaremos el nombre o nombres de los autores y la editorial. En las páginas Web indicaremos su dirección, ej.

http://aprimaria.iespana.es/index.htm http://www.ub.edu/medame/euro_map.html

Los títulos de la bibliografía podemos ordenarlos por orden alfabético, o también por orden de importancia a la hora de habernos servido para la búsqueda de información para elaborar nuestro trabajo.

- Lo último siempre que elaboraremos serán la portada, índice y bibliografía.

- Un trabajo no consiste en buscar información sobre un tema y copiarla tal cual, mezclando unas informaciones con otras. Debemos buscar primero, seleccionar aquello que nos interese de cada fuente y después componer nuestro trabajo.

- Es una buena idea hacer primero un borrador sobre algunos aspectos de nuestro trabajo: puntos que vamos a tratar, a qué aspectos vamos a dedicar más importancia...

- Si vamos a añadir imágenes, ilustraciones o dibujos en nuestro trabajo debemos hacerlo de forma ordenada, procurando que las imágenes lleven un pie de foto y que hagan referencia a algún aspecto del cual estamos hablando. Si es necesario añadir más fotos de las que cabrían en las hojas que vamos a usar, puede añadirse un anexo al final de nuestro trabajo.

- Si aparece más de una ilustración en un mismo folio, debemos colocar las imágenes de forma organizada, que no dificulten la lectura y con una distribución equilibrada (no poner las fotos juntas, todas en la misma zona del folio ni todas unas debajo de otras). Procurar alternar la distribución, una foto a la izquierda, otra a la derecha, otra a la izquierda, etc. Nos puede servir observar cómo se presentan las ilustraciones de cualquier libro de texto. 


\section{CIGARRA (Cicada orni)}

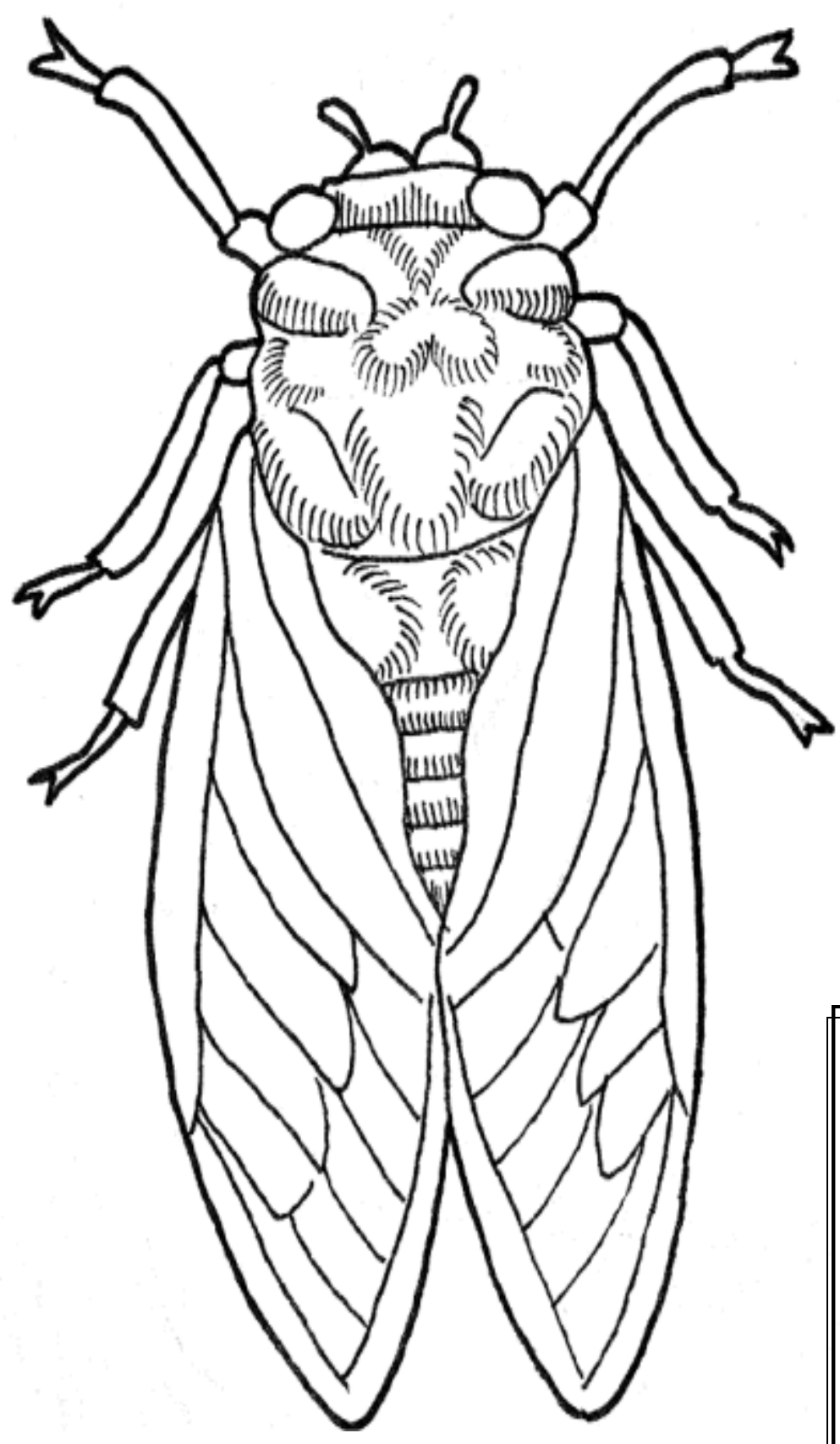

Longitud: $2,8 \mathrm{~cm}$.

Envergadura alar: $3 \mathrm{~cm}$.

Longevidad: entre 1 y 2 meses.

Hábitat: bosques.

Distribución: Europa del Sur (área mediterránea)

Costumbres: especie diurna. Alimentación: herbívora

(savia de árboles).

Reproducción: puesta superior a 300 huevos. 
ANEXO III (LISTADO DE ESPECIES A INVESTIGAR):

\section{INVERTEBRADOS:}

Escorpión

(Buthus occitanus)

Araña de los

alcornocales

(Macrothele calpeiana)

Viuda negra

(Latrodectus

tredecimguttatus)

Escolopendra

(Scolopendra cingulata)

Garrapata

(Ixodes ricinus)

Mantis o Santateresa

(Mantis religiosa)

Cigarra (Cicada orni).

Mariposa de la col

(Pieris brassicae)

Langosta egipcia

(Anacridium

aegyptium)

Típula

(Tipulidae oleracea)

Escorpión de agua

(Nepa cinérea)

Abeja carpintera

(Xylocopa violacea)

Escarabajo rinoceronte

(Oryctes nasicornis)

Libélula flecha roja

(Sympetrum

sanguineum)

Zapatero

(Gerris lacustris)

Escutígera (Scutigera

coleoptrata)

\section{PECES:}

Barbo (Barbus barbus)

Carpa

(Cyrprinus carpio)

Esturión

(Acipenser sturio)
Anguila

(Anguilla anguilla)

Trucha (Salmo trutta)

\section{ANFIBIOS:}

Sapo común

(Bufo bufo)

Sapo corredor

(Bufo calamita)

Sapillo moteado

(Pelodytes punctatus)

Ranita meridional

(Hyla meridionalis)

Gallipato

(Pleurodeles waltl)

Salamandra

(Salamandra

salamandra)

Rana verde

(Rana perezi)

\section{REPTILES:}

Salamanquesa

(Tarentola mauritanica)

Lagartija colilarga

(Psammodromus

algirus)

Lagartija ibérica

(Podarcis hispanica)

Tortuga mora

(Testudo graeca)

Galápago leproso

(Mauremys leprosa)

Culebra de escalera

(Rinechis scalaris)

Víbora hocicuda

(Vipera latasti, vipera

latastei)

Culebrilla ciega

(Blanus cinereus)
AVES:

Mirlo (Turdus merula)

Gorrión

(Passer domesticus)

Golondrina

(Hirundo rustica)

Vencejo (Apus apus)

Jilguero

(Carduelis carduelis)

Mochuelo

(Athene noctua)

Abubilla (Upupa epops)

Milano negro

(Milvus migrans)

\section{MAMÍFEROS:}

Gineta

(Genetta genetta)

Musaraña

(Crocidura russula)

Topo

(Talpa occidentalis)

Comadreja

(Mustela nivalis)

Meloncillo

(Herpestes ichneumon)

Tejón (Meles meles)

Turón

(Mustela putorius)

Gato montés

(Felis silvestris) 
ANEXO IV (PLANTILLAS DE OBSERVACIÓN Y EVALUACIÓN).

Plantilla de OBSERVACIÓN

\begin{tabular}{|c|c|c|c|c|c|c|c|c|c|c|c|c|c|c|c|c|c|c|c|}
\hline TRABAJO ESCRITO & & & & & & & & & & & & & & & & & & & \\
\hline Alumnos & 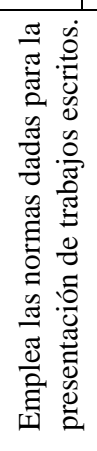 & 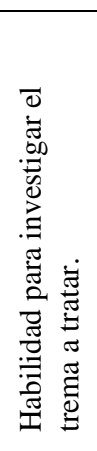 & 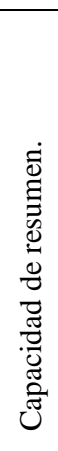 & 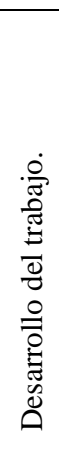 & 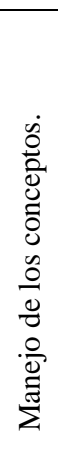 & 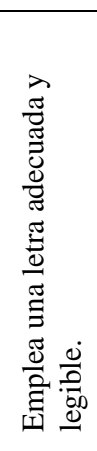 & 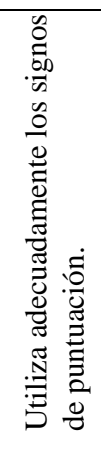 & 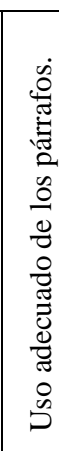 & 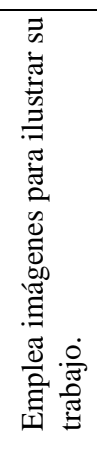 & 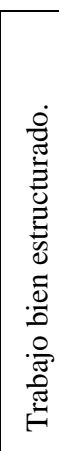 & 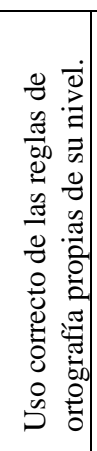 & 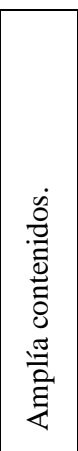 & 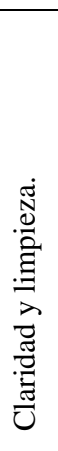 & 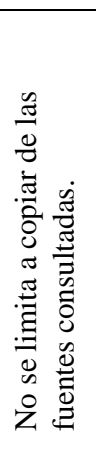 & 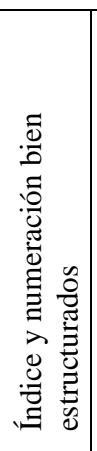 & 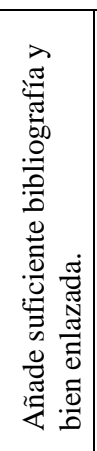 & 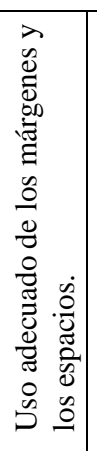 & 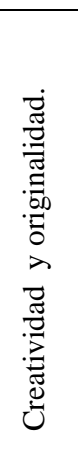 & 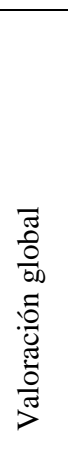 \\
\hline 1. & & & & & & & & & & & & & & & & & & & \\
\hline 2. & & & & & & & & & & & & & & & & & & & \\
\hline 3. & & & & & & & & & & & & & & & & & & & \\
\hline 4. & & & & & & & & & & & & & & & & & & & \\
\hline 5. & & & & & & & & & & & & & & & & & & & \\
\hline 6. & & & & & & & & & & & & & & & & & & & \\
\hline 7. & & & & & & & & & & & & & & & & & & & \\
\hline 8. & & & & & & & & & & & & & & & & & & & \\
\hline 9. & & & & & & & & & & & & & & & & & & & \\
\hline 10. & & & & & & & & & & & & & & & & & & & \\
\hline 11. & & & & & & & & & & & & & & & & & & & \\
\hline 12. & & & & & & & & & & & & & & & & & & & \\
\hline 13. & & & & & & & & & & & & & & & & & & & \\
\hline 14. & & & & & & & & & & & & & & & & & & & \\
\hline 15. & & & & & & & & & & & & & & & & & & & \\
\hline
\end{tabular}




\section{Plantilla de OBSERVACión}

\begin{tabular}{|c|c|c|c|c|c|c|c|c|c|c|c|c|c|c|c|}
\hline $\begin{array}{c}\text { EXPOSICIÓN ORAL } \\
\text { DEL TRABAJO. }\end{array}$ & & & & & & & & & & & & & & & \\
\hline Alumnos & 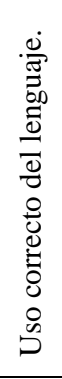 & 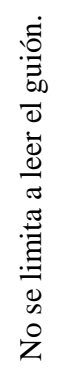 & 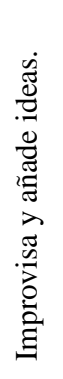 & 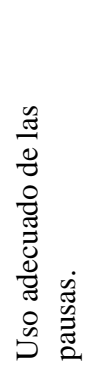 & 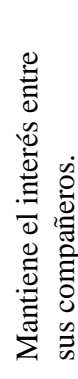 & 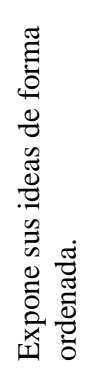 & 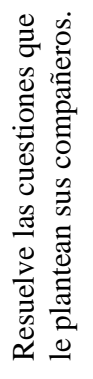 & 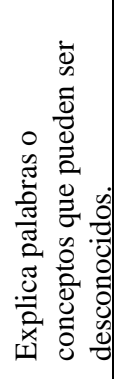 & 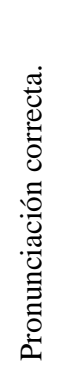 & 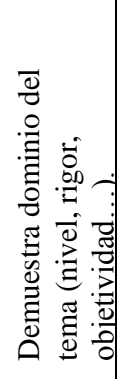 & 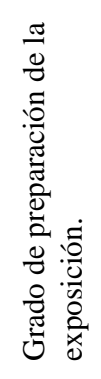 & 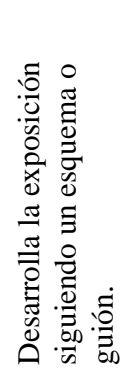 & 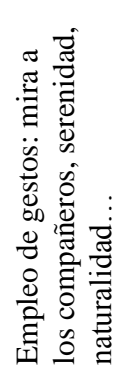 & 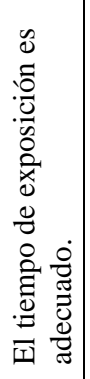 & 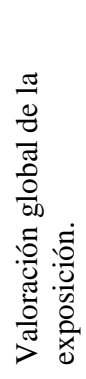 \\
\hline 1. & & & & & & & & & & & & & & & \\
\hline 2. & & & & & & & & & & & & & & & \\
\hline 3. & & & & & & & & & & & & & & & \\
\hline 4. & & & & & & & & & & & & & & & \\
\hline 5. & & & & & & & & & & & & & & & \\
\hline 6. & & & & & & & & & & & & & & & \\
\hline 7. & & & & & & & & & & & & & & & \\
\hline 8. & & & & & & & & & & & & & & & \\
\hline 9. & & & & & & & & & & & & & & & \\
\hline 10. & & & & & & & & & & & & & & & \\
\hline 11. & & & & & & & & & & & & & & & \\
\hline 12. & & & & & & & & & & & & & & & \\
\hline 13. & & & & & & & & & & & & & & & \\
\hline 14. & & & & & & & & & & & & & & & \\
\hline 15. & & & & & & & & & & & & & & & \\
\hline 16. & & & & & & & & & & & & & & & \\
\hline 17. & & & & & & & & & & & & & & & \\
\hline 18. & & & & & & & & & & & & & & & \\
\hline
\end{tabular}




\section{Plantilla de OBSERVACión}

\section{PRESENTACIÓN DE}

DIAPOSITIVAS.

\begin{tabular}{|c|c|c|c|c|c|c|c|c|c|c|c|c|c|c|c|c|}
\hline Alumnos & 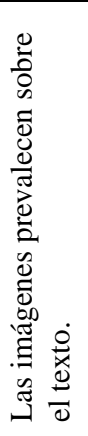 & 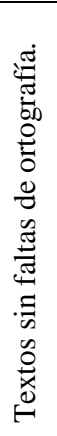 & 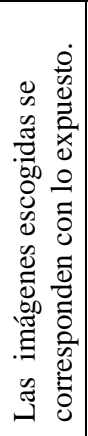 & 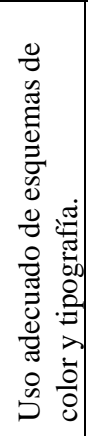 & 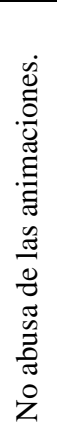 & 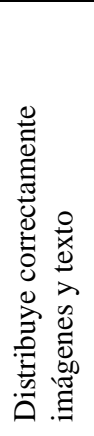 & 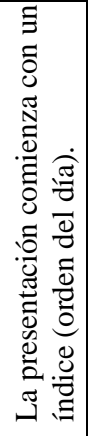 & 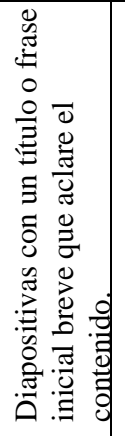 & 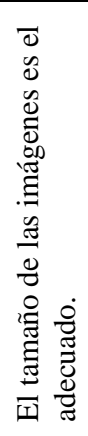 & 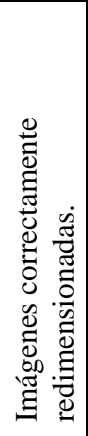 & 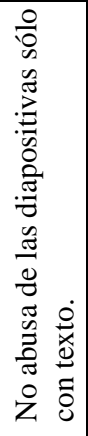 & 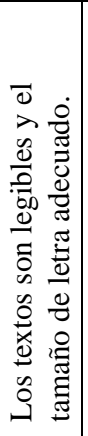 & 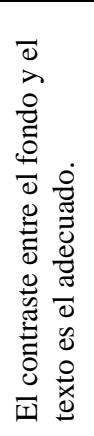 & 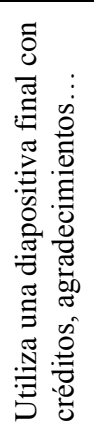 & 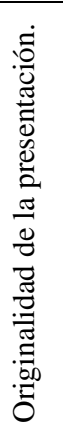 & 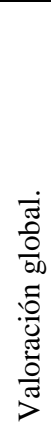 \\
\hline 1. & & & & & & & & & & & & & & & & \\
\hline 2. & & & & & & & & & & & & & & & & \\
\hline 3. & & & & & & & & & & & & & & & & \\
\hline 4. & & & & & & & & & & & & & & & & \\
\hline 5. & & & & & & & & & & & & & & & & \\
\hline 6. & & & & & & & & & & & & & & & & \\
\hline 7. & & & & & & & & & & & & & & & & \\
\hline 8. & & & & & & & & & & & & & & & & \\
\hline 9. & & & & & & & & & & & & & & & & \\
\hline 10. & & & & & & & & & & & & & & & & \\
\hline 11. & & & & & & & & & & & & & & & & \\
\hline 12. & & & & & & & & & & & & & & & & \\
\hline 13. & & & & & & & & & & & & & & & & \\
\hline 14. & & & & & & & & & & & & & & & & \\
\hline 15. & & & & & & & & & & & & & & & & \\
\hline 16. & & & & & & & & & & & & & & & & \\
\hline 17. & & & & & & & & & & & & & & & & \\
\hline 18. & & & & & & & & & & & & & & & & \\
\hline
\end{tabular}




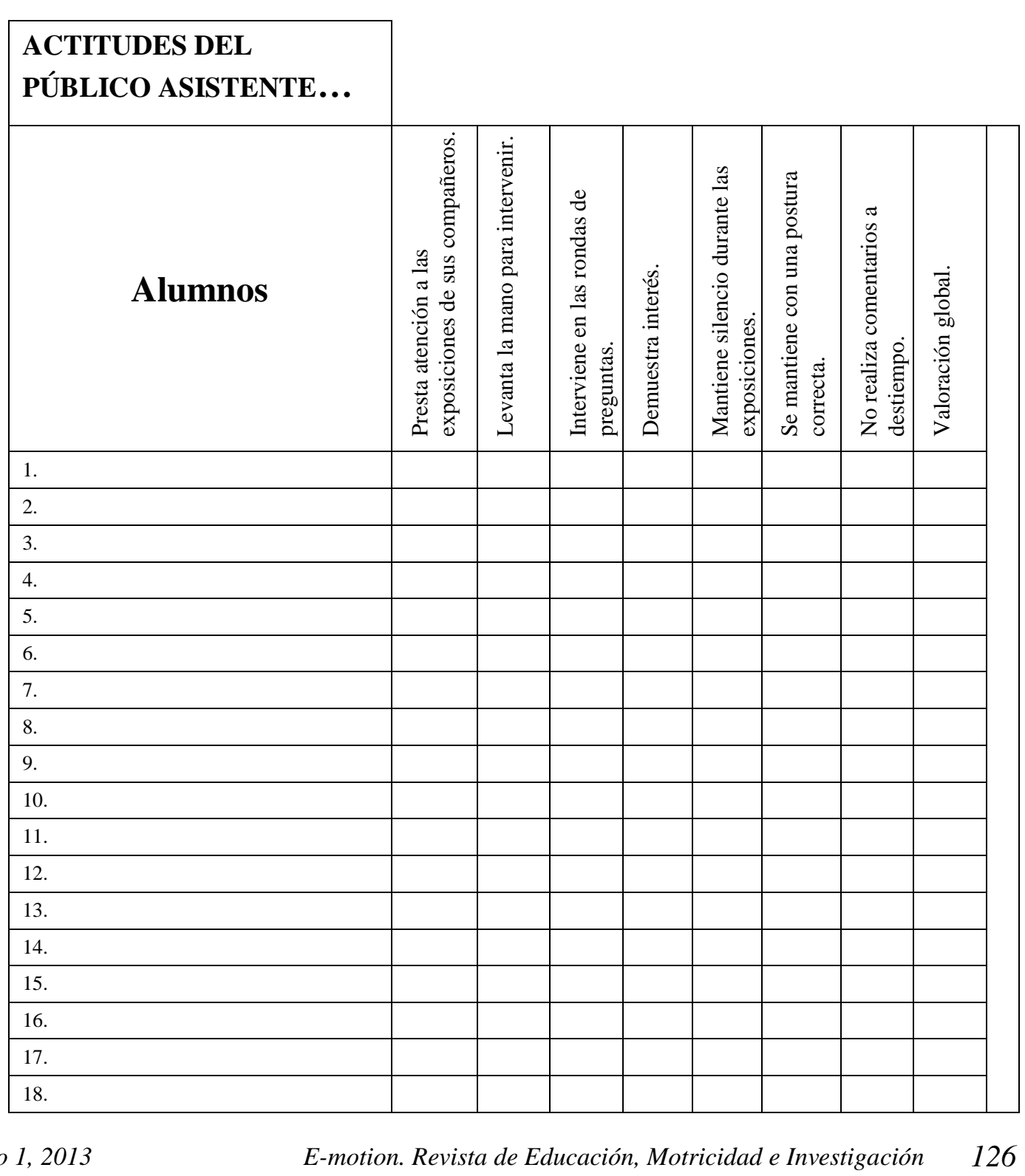




\section{Plantilla de OBSERVACión}

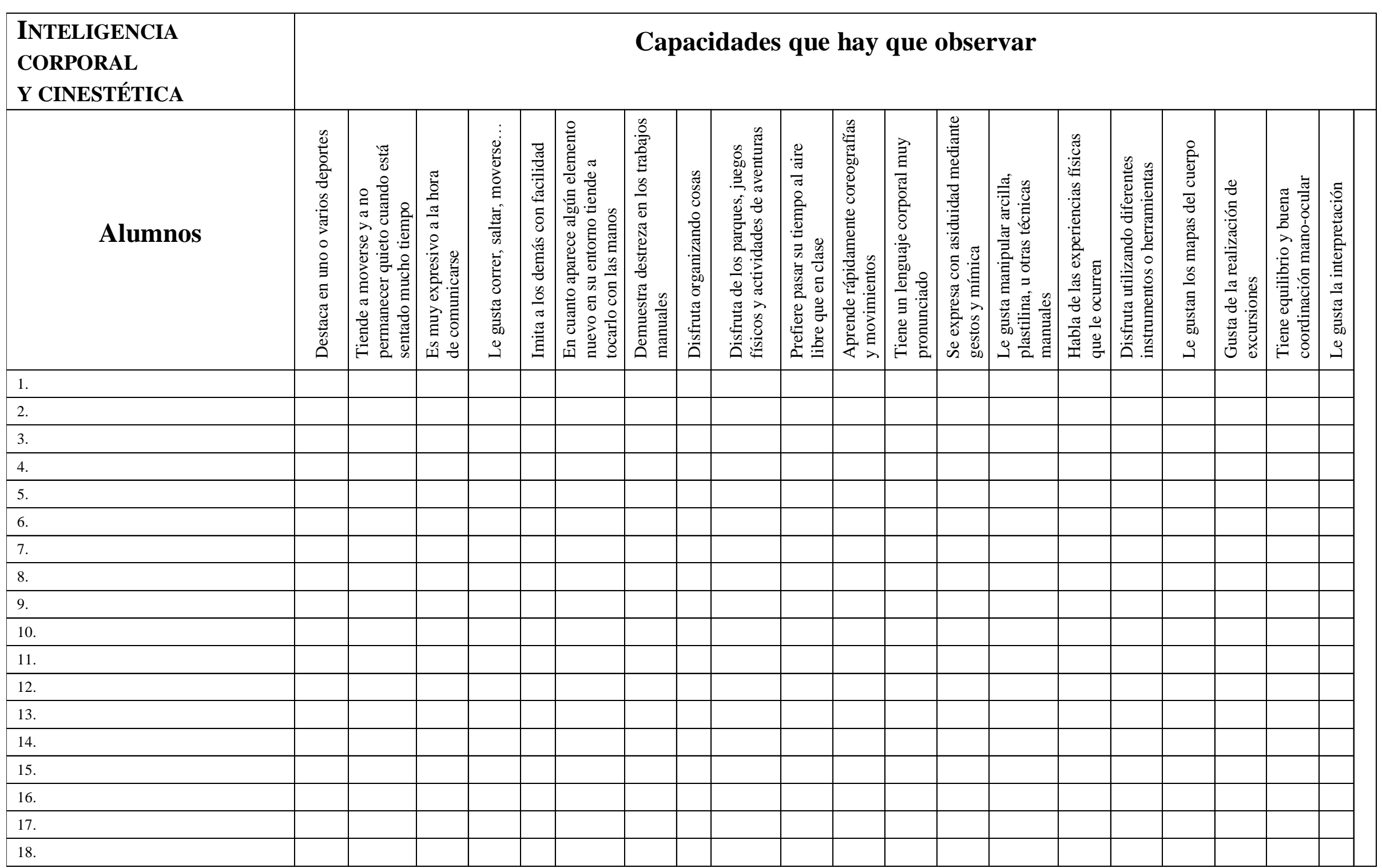

Referentes: $\mathrm{MB}=$ Muy bien; $\mathrm{B}=\mathrm{Bien} ; \mathrm{AV}=\mathrm{A}$ veces; $\mathrm{NS}=$ No es lo suyo. 